\title{
Pengaruh Jenis Bahan pada Proses Pirolisis Sampah Organik menjadi Bio-Oil sebagai Sumber Energi Terbarukan
}

\author{
M. Sigit Cahyono \\ Teknik Perminyakan, Fakultas Teknik \\ Universitas Proklamasi 45 Yogyakarta \\ e-mail: cgitk41@gmail.com
}

\begin{abstract}
Abstrak
Sampah organik merupakan potensi sumber energi yang melimpah di Indonesia. Sampah organik berupa daun dan ranting kering bisa dikonversi menjadi bahan bakar berupa bio-oil melalui proses fast pirolisis. Tujuan dari penelitian ini adalah untuk mengetahui pengaruh jenis bahan terhadap rendemen dan nilai kalor bio-oil yang dihasilkan dari proses pirolisis sampah organik. Bahan baku berupa daun dan ranting kering campuran tanaman angsana, mahoni dan mangga dengan komposisi daun bervariasi 0\%, 50\%, dan 100\%, dipotong-potong dengan ukuran maksimal $10 \mathrm{~cm}$. Kemudian bahan baku tersebut dipanaskan di dalam reaktor pirolisis pada suhu 500 C selama 1 jam. Hasil penelitian menunjukkan bahwa nilai kalor tertinggi $(5175,35 \mathrm{~J} / \mathrm{g})$ dan rendemen tertinggi $(24,5 \%)$ didapatkan pada bio-oil yang dihasilkan dari pirolisis ranting $100 \%$.
\end{abstract}

Kata kunci: Sampah Organik, Bio-oil, Pirolisis, Rendemen, Nilai Kalor

\section{PENDAHULUAN}

Pada saat ini dunia sedang mengalami krisis energi. Ketersediaan sumber energi untuk mencukupi berbagai kebutuhan, baik skala kecil dan besar, sangat terbatas. Hal ini dikarenakan masih diandalkannya sumber energi dari fosil, yaitu minyak bumi. Sifat minyak bumi yang non renewable atau tidak dapat diperbaharui membuat keadaan semakin sulit. Untuk itu diperlukan suatu pemikiran kreatif dengan menciptakan energi alternatif yang bersifat renewable, ramah lingkungan dan memiliki ketersediaan yang melimpah (Sandra, 2013).

Di sisi lain, Indonesia memiliki ketersediaan bahan organik (biomasa) berupa sisa pertanian dan perkebunan yang berlimpah. Beberapa contohnya adalah potongan kayu, sekam padi, ampas tebu, cangkang dan tandan kosong sawit, serbuk kayu, serta sabut dan cangkang kelapa. Selain itu, sampah organik dari pemukiman merupakan potensi besar lainnya yang juga amat melimpah. Data dari Kementerian Negara Lingkungan Hidup (Meneg LH) menyebutkan bahwa sepanjang tahun 2008 produksi sampah permukiman di Indonesia mencapai 167 ribu ton perhari (Radar Sulteng, 2009).

Sementara itu, di Kabupaten Sleman jumlah sampah yang ditangani oleh Dinas Kimpraswilhub Kabupaten mencapai $6.776,91 \mathrm{~m}^{3} /$ bulan, dimana sebagian besar merupakan sampah organik. Dari total sampah organik yang ada, kebanyakan berasal dari pasar, sapuan jalan dan taman terutama 
tanaman perindang (Dinas Kimpraswilhub Sleman, 2009). Data dari Seksi Pertamanan Bidang PKP Dinas Kimpraswilhub Sleman menunjukkan bahwa jumlah pohon perindang di wilayah Sleman mencapai 11.182 batang, diantaranya yang terbanyak adalah mahoni 1996 batang dan angsana 1778 batang. Selain itu, banyak terdapat pohon mangga di halaman rumah warga (Dinas Kimpraswilhub Sleman, 2008). Semua sampah organik tersebut merupakan sumber energi yang sangat potensial untuk dikembangkan di Indonesia.

Salah satu metode konversi bahan organik menjadi energi adalah menggunakan proses pirolisis. Secara ilmiah, pirolisis adalah proses dekomposisi termal bahan organik pada temperatur sekitar $350-550^{\circ} \mathrm{C}$ tanpa oksigen. Proses ini melepas 3 jenis produk, yaitu cair (Bio-oil), padat (arang), dan gas $\left(\mathrm{CO}, \mathrm{CO}_{2}, \mathrm{H}_{2}, \mathrm{H}_{2} \mathrm{O}\right.$ dan $\left.\mathrm{CH}_{4}\right)($ Heyerdahl, 2006).

Bio-oil merupakan produk utama dari proses pirolisis cepat (Fast Pyrolysis). Menurut Kristy (2007), bio-oil adalah cairan coklat gelap yang tersusun dari senyawa-senyawa teroksigenasi tinggi (highly oxigenated compounds), yang diproduksi melalui fast pyrolisis, dimana propertinya mendekati Heavy Fuel Oil (HFO) nomor 2 atau 6. Bio-oil bersifat asam dengan pH sekitar 3-4, yang mempunyai nilai kalor sebesar 75.000 BTU per galon.

Bio-oil berbeda dengan asap cair yang sudah dikenal secara umum di Indonesia. Asap cair dihasilkan dari proses slow pyrolisis dimana laju transfer panasnya sangat kecil, vapour residence time yang panjang dan sebagian besar mengandung air (70\%), fenol, asam karboksilat dan karbonil. Sedangkan bio-oil dihasilkan dari proses fast pyrolisis dimana laju transfer panasnya cepat, vapour residence time yang pendek dan sebagian besar mengandung senyawa-senyawa teroksigenasi tinggi.

Bio-oil bersifat larut sempurna dalam alkohol, dimana pelarutannya akan meningkatkan stabilitas bahan dan menurunkan viskositas sehingga cocok digunakan sebagai bahan bakar. Bio-oil tidak dapat larut dalam diesel oil, tetapi bisa diemulsifikasi dengan diesel oil. Emulsifikasi 10-30 \% biooil dalam diesel oil dapat memperbaiki stabilitas bahan bakar, memperbaiki viskositas, mengurangi tingkat korosifitas, dan meningkatkan nilai bilangan setan.

Bio-oil sebagai salah satu alternatif bahan bakar mempunyai spesifikasi yang khas, seperti disajikan dalam Tabel 1. 
Tabel 1. Spesifikasi bio-oil untuk bahan bakar

\begin{tabular}{|l|c|c|}
\hline \multicolumn{1}{|c|}{ Properties } & Spesifikasi & Keterangan \\
\hline HHV & $>70.000 \mathrm{BTU} / \mathrm{Gal}$ & Metode DINS 51900 \\
\hline Kandungan air & $<25 \%$ & ASTM D1744 \\
\hline Viskositas & $10-150 \mathrm{cP} @ 50^{\circ} \mathrm{C}$ & ASTM D445 \\
\hline Spesifik gravity & $1,2 @ 15^{\circ} \mathrm{C}$ & ASTM D4052 \\
\hline Elemental analisis: & Range & Average \\
\hline Karbon & $51,5-58,3$ & 54,5 \\
\hline Hidrogen & $5,5-6,8$ & 6,4 \\
\hline Nitrogen & $0,07-0,40$ & 0,2 \\
\hline Sulfur & $<0,07$ & 0,0005 \\
\hline Debu & $0,13-0,21$ & 0,16 \\
\hline
\end{tabular}

Sumber: Dynamotive (2006)

Pirolisis cepat (fast pyrolysis) merupakan teknik yang relatif baru untuk menghasilkan energi terbarukan. Dibandingkan dengan pembakaran dan gasifikasi serta karbonisasi, yang juga merupakan proses pirolisis lambat yang telah dipraktekkan secara luas dan komersial, pirolisis biomassa terutama pirolisis cepat masih berada dalam tahap pengembangan awal (Poerwanto, 2009).

Penelitian dan pengembangan proses pirolisis cepat bahan organik dengan suplai kalor konvensional telah banyak dilakukan. Brown dan Holmgren (Brown, 2008) telah mengembangkan perangkat yang menghasilkan energi dalam bentuk padat, cair dan gas dengan komposisi 12-15\% arang, 60-70\% cair, dan 13-25\% gas. Proses berlangsung cepat antara 0,5 - 2 detik untuk mendapatkan temperatur moderat $400-500^{\circ} \mathrm{C}$ pada tekanan atmosfer. Hasil minyak pirolisis ini dapat langsung digunakan pada mesin diesel stasioner, atau diproses lanjut. Prof. Yi Weiming dari Shandong University of Technology (Weiming, 2006) telah mengembangkan beberapa prototipe skala umpan 50-200 kg/jam dan melakukan berbagai penelitian optimasi proses pirolisis dan konfigurasi sistem maupun variasi reaktor prosesnya.

Penelitian pirolisis di dalam negeri telah dilakukan beberapa perguruan tinggi dalam skala lab, merujuk beberapa referensi yang diperoleh. Penelitian tugas akhir sarjana oleh Ekasurya Poerwanto dari ITB (Poerwanto, 2009), merancang reaktor batch pirolisis serbuk gergaji. Proses berlangsung pada $300-450^{\circ} \mathrm{C}$ selama $30-60$ menit, menghasilkan produk pirolisis yang mengandung air, asam 
karboksilat, dan senyawa aromatik. Disimpulkan dari penelitian tersebut, hasil yang diperoleh relatif sama dengan hasil yang diperoleh dari penelitian pirolisis biomassa lain.

Irawan Noor (Noor, 2011) meneliti pengaruh bahan baku serbuk gergaji kayu jati dan suhu terhadap rendemen bio-oil serta nilai kalor yang dihasilkan. Hasil penelitian menunjukkan bahwa rendemen bio-oil tertinggi dari limbah serbuk gergaji kayu jati dihasilkan pada temperatur $500^{\circ} \mathrm{C}$ yaitu sebesar $21,99 \%$ dan nilai kalor yang dihasilkan yaitu 7497,52 Kal/g. Nilai kalor ini lebih tinggi dibandingkan nilai kalor dari kayu dan batubara.

Dalam proses pirolisis, komposisi produk akhir sangat bergantung pada komposisi bahan dan kondisi proses pirolisis (Fachrizal dkk, 2013). Oleh karena itu, untuk mengetahui pengaruh jenis bahan sampah organik berupa daun dan ranting kering, terhadap kuantitas (rendemen) dan kualitas (nilai kalor) produk bio-oil yang dihasilkan, perlu dilakukan sebuah penelitian agar bisa dijadikan dasar dalam perencanaan mesin pirolisis skala yang lebih besar.

\section{METODE PENELITIAN}

a. Bahan Penelitian

Bahan baku dari sampah organik berupa daun dan ranting tanaman angsana, mahoni dan mangga yang didapatkan dari Lokasi Daur Ulang Sampah (LDUS) Tambak Boyo, Sleman. Bahan baku tersebut dikeringkan sampai kadar air sekitar 15\%, kemudian dicacah sampai ukuran maksimal $10 \mathrm{~cm}$. Dalam satu kali pirolisis, digunakan daun dan atau ranting kering sebanyak $1 \mathrm{~kg}$ yang dipirolisis pada suhu $500^{\circ} \mathrm{C}$ selama 1 jam.

b. Alat Penelitian

Peralatan yang digunakan berupa satu set alat pirolisis, seperti ditunjukkan dalam Gambar 1.

c. Jalannya Penelitian

Tahap pertama adalah memasukkan bahan baku yang telah disiapkan ke dalam tabung pirolisis (retort), kemudian memasang tutupnya yang telah dilengkapi temperature dan pressure indicator. Di sisi lain, bahan bakar yang disiapkan dimasukkan ke tungku pembakaran (kiln). Setelah itu, alat dirangkai dengan memasukkan retort ke dalam kiln dan memasang pipa uap untuk mengalirkan uap menuju kondensor.

Tahap kedua setelah peralatan terpasang adalah melakukan pembakaran, dimana penyalaan awal dilakukan dari bagian bawah kiln dengan membakar jerami yang mudah terbakar, sehingga bahan bakar yang terdapat di dalam kiln juga ikut terbakar dengan cepat. Pada saat pembakaran, 
dilakukan pengamatan terhadap suhu dan tekanan di dalam retort dimana suhu dijaga sekitar $500^{\circ} \mathrm{C}$ selama 1 jam, dengan cara memperkecil lubang udara kiln jika suhu naik lebih dari $500^{\circ} \mathrm{C}$ serta menambahkan bahan bakar apabila suhu turun di bawah $500^{\circ} \mathrm{C}$.

Pada saat pirolisis, terjadi penguapan volatile matter dan penguraian bahan organik menghasilkan uap dan arang. Uap yang terbentuk dialirkan menuju kondensor untuk didinginkan agar terbentuk bio-oil, sedangkan sisa gas yang non condensable dikeluarkan ke udara. Sedangkan arang akan tertinggal di dalam retort dan akan dikeluarkan setelah selesai percobaan. Bio-oil yang terbentuk kemudian ditampung dalam penampung lalu diukur volume dan nilai kalornya menggunakan alat Oxygen Bomb Calorimeter.

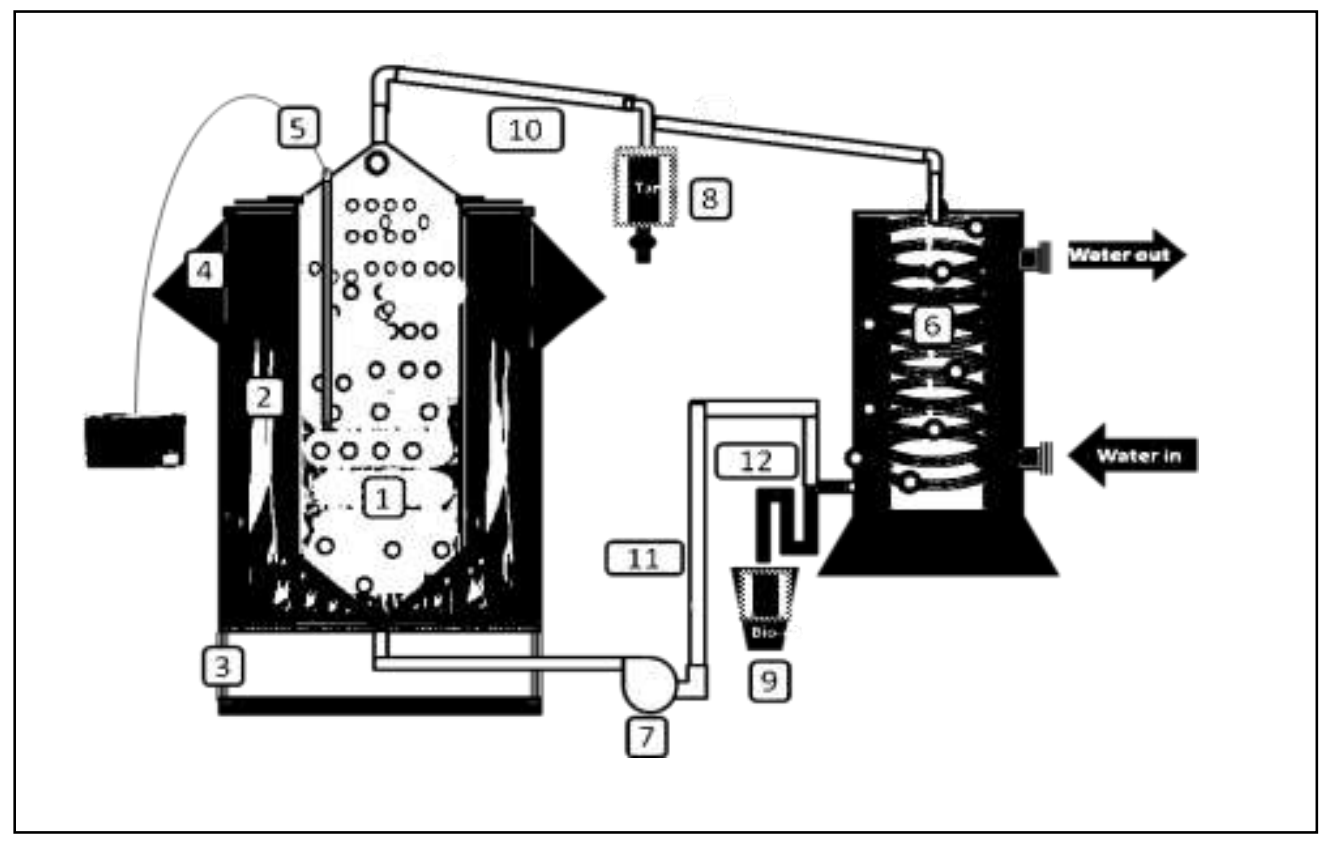

Gambar 1. Satu set alat pirolisis

Keterangan :
1. Tabung pirolisis (Retort)
7. Blower
2. Tungku pembakaran (Kiln)
8. Penampung tar
3. Lubang udara
9. Penampung bio-oil
4. Lubang bahan bakar
10. Pengukur tekanan
5. Termokopel
11. Pipa gas recycle
6. Tabung Kondensasi
12. Pipa bio-oil

\section{HASIL PENELITIAN}

\section{a. Karakteristik Bahan Baku}

Untuk mengetahui kondisi awal bahan baku, dilakukan pengujian nilai kalor, kadar air dan kadar abu di Laboratorium Kimia dan Biokimia Pusat Studi Pangan dan Gizi UGM, dengan hasil disajikan pada Tabel 2. 
Tabel 2. Hasil analisa bahan baku

\begin{tabular}{|c|c|c|c|}
\hline No & Analisa & Daun kering & Ranting kering \\
\hline 1 & Nilai kalor (J/g) & 14.968 & 17.083 \\
\hline 2 & Kadar Air (\%) & 12,53 & 14,56 \\
\hline 3 & Kadar Abu (\%) & 11,34 & 13,89 \\
\hline
\end{tabular}

Tabel 2 menunjukkan bahwa nilai kalor campuran ranting kering tanaman angsana, mahoni dan mangga lebih besar daripada campuran daun kering tanaman yang sama. Begitu juga dengan kadar air dan kadar abu dari ranting kering yang lebih besar daripada daun kering. Hal ini disebabkan karena kandungan senyawa kimia di dalam ranting lebih kompleks dibandingkan kandungan kimia daun (Soenardi, 1995).

\section{b. Proses Pirolisis}

Bio-oil terbentuk pada pirolisis biomassa pada suhu sekitar $500^{\circ} \mathrm{C}$ selama 1 jam, dimana kenaikan suhu dari keadaan standar $\left(30^{\circ} \mathrm{C}\right)$ ke suhu $500^{\circ} \mathrm{C}$ diusahakan terjadi secepat mungkin (Bridgewater, 2007). Proses kenaikan panas yang terjadi selama pirolisis ditunjukkan dalam Gambar 2.

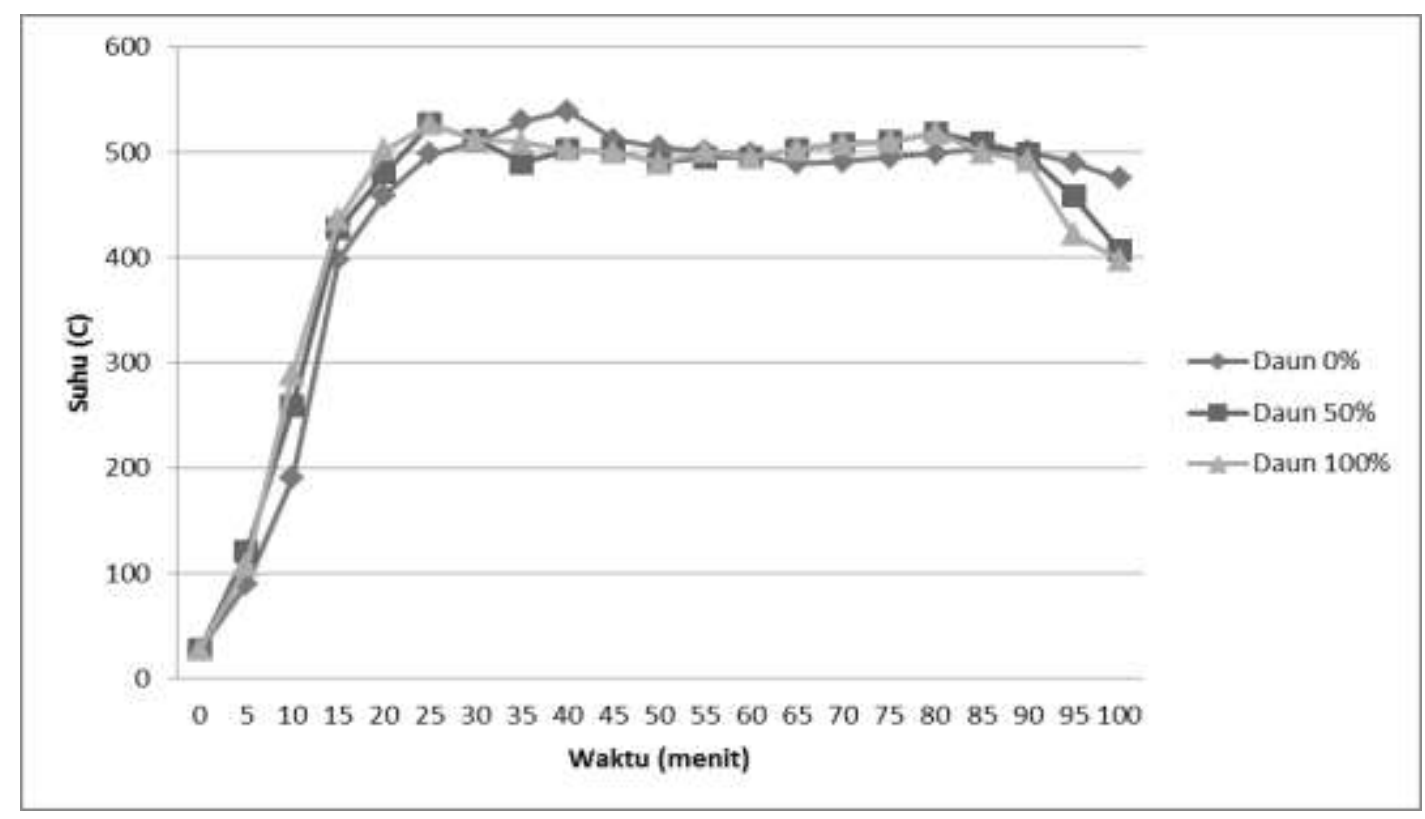

Gambar 2. Kenaikan suhu pada proses pirolisis

Pada gambar 2 dapat dilihat bahwa kenaikan suhu selama pirolisis dari suhu kamar sampai $500{ }^{0} \mathrm{C}$ berlangsung dalam waktu sekitar 20 menit. Nilai ini lebih cepat dari proses pirolisis biasa yang menghasilkan produk asap cair dan arang yang terjadi dalam waktu sekitar 90 menit (Nisandi, 2007). 


\section{c. Pengaruh Bahan Baku terhadap Rendemen Bio-oil}

Rendemen bio-oil yang dihasilkan dalam penelitian ini disajikan pada Gambar 3.

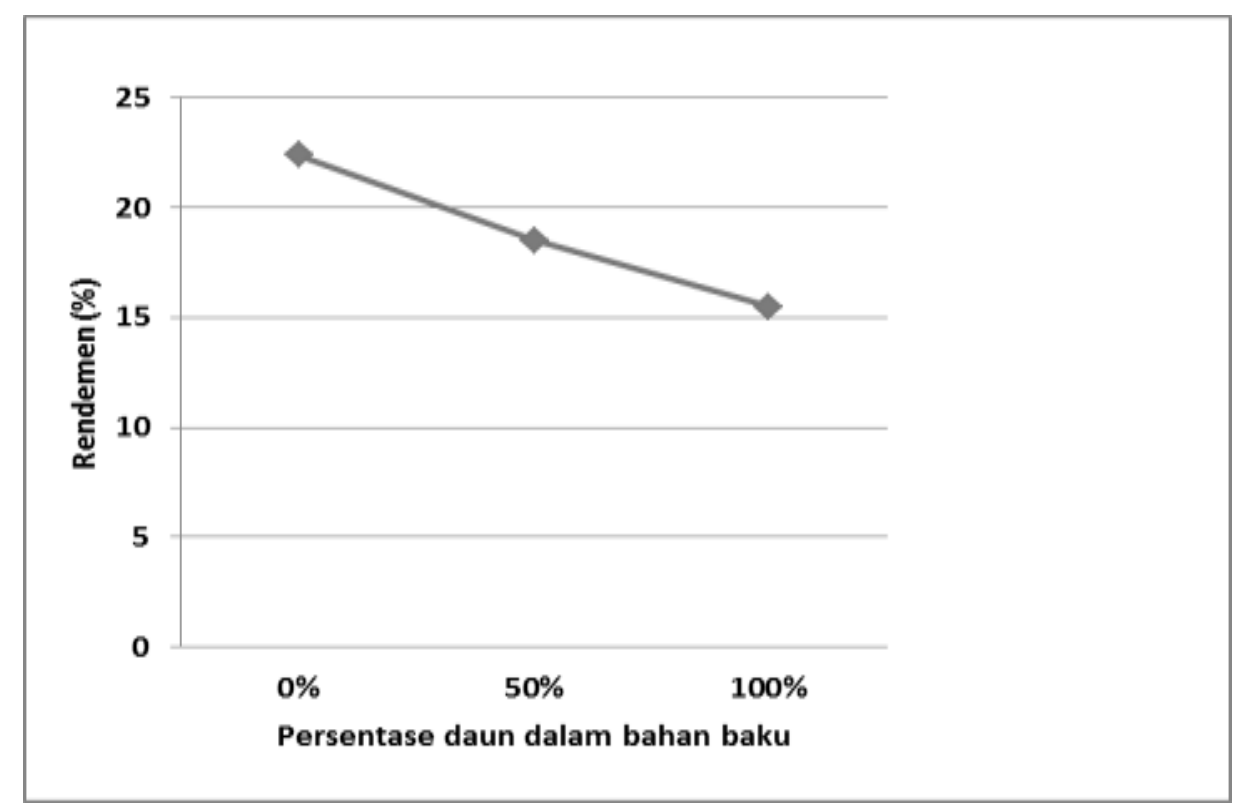

Gambar 3. Pengaruh bahan baku terhadap rendemen bio-oil

Dari Gambar 3 dapat dilihat bahwa nilai rendemen tertinggi dihasilkan untuk bahan baku daun 0\% (atau $100 \%$ ranting), yaitu sebesar 24,3\%. Sedangkan rendemen terendah dihasilkan untuk bahan baku daun $100 \%$ (atau $0 \%$ ranting), yaitu sebesar $15,5 \%$.

Rendemen bio-oil pada pirolisis 100\% ranting lebih tinggi daripada 100\% daun, karena kandungan senyawa kimia di dalam ranting lebih kompleks dibandingkan kandungan kimia daun (Soenardi, 1995). Hal ini akan menyebabkan proses konversi bahan organik pada ranting lebih banyak daripada daun.

Akan tetapi, rendemen bio-oil pada penelitian ini masih jauh dibawah rendemen yang dihasilkan pada proses fluidized bed yaitu sebesar 70\% (Bridgewater, 2007). Hal ini disebabkan karena pada proses fluidized bed terjadi fluidisasi material yang berukuran sangat kecil di dalam reaktor dengan bantuan gas inert bertekanan tinggi, sehingga proses transfer panas bisa terjadi dengan sangat cepat, uap yang terbentuk juga semakin besar dan cepat terkondensasi. Hal ini berbeda dengan penelitian ini karena tidak adanya gas inert yang digunakan untuk fluidisasi bahan di dalam reaktor. 


\section{d. Pengaruh Bahan Baku terhadap Nilai Kalor Bio-oil}

Nilai kalor bio-oil yang dihasilkan dalam penelitian ini disajikan pada Gambar 4.

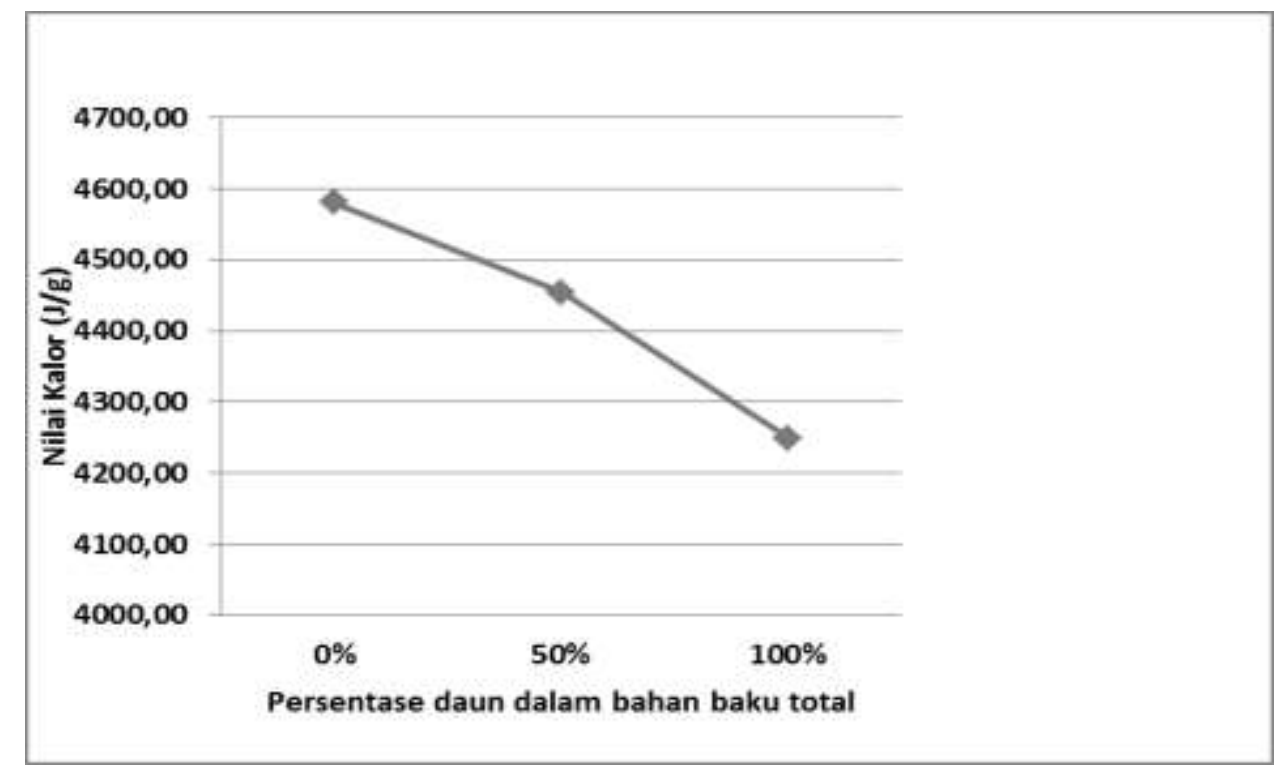

Gambar 4. Pengaruh bahan baku terhadap nilai kalor bio-oil

Dari gambar 4 dapat dilihat bahwa nilai kalor tertinggi dihasilkan untuk bahan baku daun 0\% (atau 100\% ranting), yaitu sebesar 5.175,35 J/g. Sedangkan nilai kalor terendah dihasilkan untuk bahan baku daun 100\% (atau 0\% ranting), yaitu sebesar 4.249,20 J/g. Nilai kalor bio-oil dari pirolisis ranting lebih besar daripada daun, disebabkan karena bahan baku awal berupa ranting sebelum dipirolisis memiliki nilai kalor yang lebih besar dibandingkan daun.

Akan tetapi, nilai kalor bio-oil pada penelitian ini masih jauh dibawah rendemen yang dihasilkan pada proses fluidized bed yaitu sebesar $18.000 \mathrm{~J} / \mathrm{g}$ (Bridgewater, 2007). Hal ini disebabkan karena pada proses fluidized bed terjadi fluidisasi material yang berukuran sangat kecil di dalam reaktor dengan bantuan gas inert bertekanan tinggi, sehingga proses transfer panas bisa terjadi dengan sangat cepat, uap yang terbentuk juga semakin besar dan cepat terkondensasi sehingga produk biooil mempunyai nilai kalor lebih tinggi. Hal ini berbeda dengan penelitian ini karena tidak menggunakan gas inert untuk fluidisasi bahan yang ada di dalam reaktor.

\section{KESIMPULAN}

1. Sampah organik berupa daun dan ranting tanaman bisa dikonversi menjadi bio-oil sebagai bahan bakar alternatif menggunakan proses pirolisis. 
2. Rendemen bio-oil terbesar dihasilkan dari proses pirolisis $100 \%$ ranting kering yaitu sebesar $24,3 \%$, lebih tinggi dibandingkan bahan baku daun $100 \%$ yaitu sebesar $15,5 \%$.

3. Pirolisis ranting kering akan menghasilkan bio-oil dengan nilai kalori 5.175,35 J/g, lebih besar daripada nilai kalori bio-oil dari daun kering yang sebesar 4.249,20 J/g

\section{DAFTAR PUSTAKA}

Anonim, 2008, Laporan Rekapitulasi Pohon Perindang di Kabupaten Sleman, Dinas Kimpraswilhub Kabupaten Sleman, Sleman, Yogyakarta

Anonim, 2009, Laporan Rekapitulasi Pengangkutan Sampah di Kabupaten Sleman, Dinas Kimpraswilhub Kabupaten Sleman, Sleman, Yogyakarta

Bridgewater, 2007, Biomass Fast Pyrolysis, Aston University, Birmingham.

Brown, R.C., and Holmgren, J., 2008, Fast Pyrolysis and Bio-oil Upgrading, Iowa State University and UOP Honeywell Co.

Dinamotive, 2006, The Bio-oil Information Book, edisi 13 Maret. Dynamotive Energy System Corporation, Vancouver (BC), Canada.

Fachrizal, dkk, 2013, Studi Pemanfaatan Gelombang Mikro pada Pengembangan Teknologi Pirolisis Biomassa, Jurnal Ilmiah Teknologi Energi, Volume 1 nomor 16 Edisi Februari 2013, Hal 20-33

Heyerdahl, P.H., and Geoffrey, G., 2006. Distributed Biomass Conversion, Norwegian University, Oslo

Kristy M., 2007, Biooils: Feedstocks, Process and Potential for Synthetic Diesel, BBI International, Colorado

Nisandi, 2007, Pengaruh Massa Bahan dalam Ruang Pengarangan serta Komposisi Campuran Bahan terhadap Kualitas Briket Arang yang Dihasilkan pada Pirolisis Sampah Organik, Tesis Teknologi Pengelolaan dan Pemanfaatan Sampah/limbah Perkotaan (TP2SLP) Magister Sistem Teknik (MST), Universitas Gadjah Mada, Yogyakarta

Noor, 2011, Optimasi Suhu Operasi pada Produksi Bio-Oil dari Limbah Serbuk Gergaji Kayu Jati (Tectona Grandits Linn F), Tesis Teknologi Industri Kecil dan Menengah (TIKM) Magister Sistem Teknik (MST), Universitas Gadjah Mada, Yogyakarta

Poerwanto, 2009, Perancangan Reaktor dan Pengembangan Prosedur Operasi Pirolisis Serbuk Gergaji untuk Menghasilkan Bio-oil, Tugas Akhir, ITB Bandung 
Radar Sulteng Online, 2009, Sampah Indonesia 167 Ribu Ton Per Hari. Diakses melalui http://www.radarsulteng.com/berita/index.asp?Berita=Utama\&id=48959, 23 Februari 2009

Sandra, dkk., 2013, Konversi Cangkang Sawit menjadi Bio-oil menggunakan Katalis Ni.Mo/Lempung Cengar, Tugas Akhir Program Studi Teknik Kimia S1, Fakultas Teknik. Universitas Riau

Soenardi, 1995, Kimia Kayu, Bagian Penerbitan Fakultas Kehutanan UGM, Yogyakarta

Weiming, 2006, Biomass Liquifaction Technology, Shandong University of Technology, Shandong, China 